(2)

OPEN ACCESS

\section{Drug sellers' knowledge and practices, and client perspectives after an intervention to improve the quality of safe abortion care outside of formal clinics in Nigeria}

- Additional supplemental material is published online only. To view, please visit the journal online (http://dx.doi. org/10.1136/bmjsrh-2020200955).

${ }^{1}$ Research \& Evaluation, Ipas, Abuja, FCT, Nigeria

${ }^{2}$ Chapel Hill, North Carolina, USA ${ }^{3}$ Technical Excellence, Ipas, Chapel Hill, North Carolina, USA ${ }^{4}$ Abuja, Nigeria

\section{Correspondence to} Yinka Abiola Adojutelegan, Ipas, Abuja, Nigeria; yinka.abiola@ gmail.com

Received 11 November 2020 Revised 30 March 2021 Accepted 5 April 2021

\section{A Check for updates}

(c) Author(s) (or their employer(s)) 2021. Re-use permitted under CC BY-NC. No commercial re-use. See rights and permissions. Published by BMJ.

To cite: Adojutelegan YA, Coughlin AJ, Shellenberg K, et al. BMJ Sex Reprod Health Published Online First: [please include Day Month Year]. doi:10.1136/

bmjsrh-2020-200955

\section{ABSTRACT}

Background In Nigeria, where abortion is legally restricted, individuals seek medication abortion drugs, including misoprostol, directly from pharmacies or drug sellers. However, knowledge of drug sellers or patent medicine vendors (PMVs) dispensation practices and women's experience with self-management is limited and research suggests poor quality of services. This study assesses the knowledge and practices of PMVs and women's experiences after a harm reduction intervention to improve the provision of medication abortion using misoprostol.

Methods We conducted a retrospective descriptive analysis of anonymised logbook data collected from 141 Nigerian PMVs who provided misoprostol for abortion to 4924 clients between February 2015 and July 2018. We conducted a descriptive analysis of self-reported misoprostol dispensation practices with data from a crosssectional survey of PMVs $(n=120)$ from June 2016 to December 2018. We collected data on women's experience obtaining misoprostol from 37 PMVs through a cross-sectional survey of women ( $n=260)$ from 4-19 June 2018.

Results For clients where the misoprostol dose dispensed was recorded ( $n=3784$ ), $86 \%$ of clients were given $800 \mu \mathrm{g}$ or more misoprostol, pain medication (97\%) and a contraceptive method (92\%). Most clients with an outcome recorded in the logbook $(n=4431)$ had a complete abortion (86\%). Almost all women reported that they would return to the PMV for future services (99\%).

Conclusions The majority of PMVs dispensed misoprostol in appropriate dosages and provided clients with information on drug administration and methods of contraception. Interventions designed to improve PMVs' best practices around
\end{abstract}

\section{Key messages}

- Patent medicine vendors (PMVs) can be an important source of abortion care in Nigeria where abortion is legally restricted.

- The majority of PMVs in this intervention dispensed misoprostol in appropriate dosages and provided clients with information on drug administration and methods of contraception.

- Interventions designed to improve PMVs' best practices around the provision of abortion care may help ensure the quality of services received by clients.

the provision of abortion care may help ensure the quality of services received by clients.

\section{INTRODUCTION}

Medication abortion, or the use of pills to end a pregnancy, is a safe and effective method that is increasingly available worldwide. World Health Organization (WHO) guidelines recommend the use of mifepristone-misoprostol for medication abortion or, in settings where mifepristone is not available, misoprostol alone. ${ }^{1}$ Where abortion is legally restricted or access to services is limited, individuals may seek mifepristone and/or misoprostol directly from a pharmacy or drug shop and self-manage their abortion. WHO guidelines support self-management with mifepristone-misoprostol when access to a trained provider is available but, given limited evidence, does not endorse 
self-management with misoprostol alone. ${ }^{1}$ Evidence on people's experience obtaining misoprostol or mifepristone-misoprostol directly from pharmacies or drug sellers is limited. ${ }^{2-4}$

Abortion in Nigeria is legally allowed only to save a woman's life. ${ }^{5}$ However, a study conducted in 2012 reported an annual incidence of 1.25 million abortions. ${ }^{6}$ More recent data estimate nearly 1.8 million abortions annually or 41.1 per 1000 women aged 15-49 years; when including the experience of respondents' closest confidantes, the number of likely abortions in Nigeria rose to 2.7 million. $^{7}$ Nigeria has one of the highest maternal mortality rates in the world and unsafe abortion is a major contributor to maternal morbidity and mortality. ${ }^{8-10}$

Given Nigeria's restrictive abortion law, access to safe abortion services is limited in public hospitals where care is relatively affordable. ${ }^{6}$ Instead, individuals seek care elsewhere, including by purchasing medications directly from pharmacies or drug sellers. In Nigeria, patent and proprietary medicine vendors or PMVs play an important role in the provision of basic healthcare services ${ }^{11} 12$ including reproductive health, ${ }^{13-16}$ though knowledge of their role in abortion care is limited. ${ }^{3}$ PMVs are persons without formal training in pharmacy who sell orthodox pharmaceutical products in retail for profit. Many PMVs are known to have medical training, though this is not a requirement, and they often operate from shops. ${ }^{12}$

Misoprostol was first registered in Nigeria in 2006 for the treatment of postpartum haemorrhage. ${ }^{17} \mathrm{~A}$ survey conducted in pharmacies and drug outlets in Lagos and Abuja in 2006 found misoprostol not well known or widely available. ${ }^{18}$ Over a decade later, research suggests misoprostol is more widely sold in drug outlets and is increasingly used for abortion. ${ }^{3} 19$ In 2014, the national task shifting guidelines allowed PMVs to stock misoprostol for the management of postpartum haemorrhage. ${ }^{20}$ Mifepristone was registered in Nigeria in 2017 and is increasingly available and used for abortion care.

Given the high unsafe abortion rate and evidence of misoprostol availability and dispensing for abortion by PMVs, from 2015 to 2018 Ipas worked with Nigerian Ministry of Health officials in three states to improve PMVs' knowledge about and provision of misoprostol for comprehensive abortion care The present study uses monitoring and evaluation data collected during this intervention to: (1) document the post-training knowledge and practices for the provision of misoprostol for abortion by participating PMVs and (2) assess the experiences and satisfaction of women who obtained either abortion or post-abortion care from a participating PMV.

\section{METHODS \\ Setting}

Ipas collected data as part of the monitoring and evaluation activities of a harm reduction intervention designed to improve comprehensive abortion care by PMVs across three states in Nigeria from 2015 to 2018. PMVs were selected from a sampling frame developed through a physical search of PMV shops and snowball recruitment. Ipas recruited PMVs for the intervention if they were a nurse/midwife, community health extension worker (CHEW) or community health officer $(\mathrm{CHO})$ with a current practising license. Participants were required to operate a patent medicine shop; be willing to attend training; already dispense or sell misoprostol and be willing to dispense and sell misoprostol for abortion post-training; and provide contraceptive services to willing clients. All participants attended a 3-day course training on abortion and post-abortion misoprostol regimens, screening, eligibility and contraindications, expected and potential adverse effects, complications and follow-up care. The intervention had 183 participating PMVs. Each PMV was trained on medication abortion provision using misoprostol and were linked with misoprostol suppliers and trained clinicians for referral and treatment of complications. Participants were required to record details about care provided to clients who received misoprostol in a logbook without any client's personal information (Figure 1S).

\section{Project design and data collection}

The intervention included two components: (1) assessments of PMV's post-training knowledge and practice undertaken as part of routine monitoring and evaluation with (A) review of client logbooks maintained by PMVs during the intervention and (B) a cross-sectional survey of PMV knowledge, attitude and practices around misoprostol provision and (2) a cross-sectional survey of women who purchased misoprostol from a selected group of the trained PMVs.

Review of logbook service records

Online supplemental figure 1S describes the intervention sample. Ipas trained 183 PMVs and 146 trained PMVs collected data prospectively on their misoprostol dispensation. Three PMVs who did not dispense misoprostol for induced abortion and two PMVs with incomplete logbook records were excluded from the analysis. Logbook data from 141 vendors collected from 1 February 2015 to 1 July 2018 are reported here.

Assessment of PMV knowledge and practice of provision of misoprostol for abortion

During the intervention, PMVs maintained a logbook recording the dispensation of misoprostol including dispensation date, client age and gestational age, service provided (post-abortion care or induced abortion), dose dispensed, pain management and contraception provided, and abortion outcome (ie, referred to another provider, complete abortion or abortion with complications). Ipas staff collected logbook entries at quarterly monitoring visits and entered data into Epidata. 
Table 1 Description of abortion clients, medications dispensed and abortion outcome as recorded in patent medicine vendor logbooks*

\begin{tabular}{|c|c|c|}
\hline \multirow[b]{2}{*}{ Variable } & \multicolumn{2}{|c|}{$\begin{array}{l}\text { Among clients provided } \\
\text { misoprostol for induced } \\
\text { abortion }(n=4924)\end{array}$} \\
\hline & $\mathbf{n}$ & $\%$ \\
\hline \multicolumn{3}{|l|}{ Age of client (years) †† } \\
\hline$\leq 19$ & 965 & 19.6 \\
\hline $20-24$ & 1457 & 29.6 \\
\hline $25+$ & 2498 & 50.8 \\
\hline \multicolumn{3}{|c|}{ Recorded gestational age of pregnancy (weeks) } \\
\hline$<13$ & 4220 & 85.7 \\
\hline$\geq 13$ & 205 & 4.2 \\
\hline Missing & 499 & 10.1 \\
\hline \multicolumn{3}{|l|}{ Misoprostol dose dispensed $(\mu \mathrm{g})$} \\
\hline$<800$ & 533 & 10.8 \\
\hline 800 & 2313 & 47.0 \\
\hline $1000-1400$ & 132 & 2.7 \\
\hline $1600-2400$ & 792 & 16.1 \\
\hline$>2600$ & 14 & 0.3 \\
\hline Missing & 1140 & 23.2 \\
\hline Pain management provided & 4876 & 99.0 \\
\hline \multicolumn{3}{|l|}{ Contraception provided $\neq$} \\
\hline Short-term method & 3511 & 71.8 \\
\hline Long-term method§ & 974 & 19.9 \\
\hline No method & 403 & 8.2 \\
\hline \multicolumn{3}{|l|}{ Abortion outcome } \\
\hline Complete abortion & 4224 & 85.8 \\
\hline $\begin{array}{l}\text { Abortion with complication } \\
\text { managed by PMV }\end{array}$ & 33 & 0.7 \\
\hline $\begin{array}{l}\text { Abortion with complication } \\
\text { referred to another provider }\end{array}$ & 174 & 3.5 \\
\hline Missing & 493 & 10.0 \\
\hline \multicolumn{3}{|c|}{$\begin{array}{l}\text { *Data on post abortion care (PAC) clients excluded because of observec } \\
\text { limitations in accurate PAC documentation. } \\
\text { †Data on age were missing for four clients. } \\
\text { fData on contraception provided were missing for } 36 \text { clients. } \\
\text { §Long-term methods included primarily women who received implants } \\
\text { and a few who received intrauterine contraceptive devices. } \\
\text { PMV, patent medicine vendor. }\end{array}$} \\
\hline
\end{tabular}

Trained facilitative supervisors visited each shop quarterly and used a structured survey to assess misoprostol stocking and dispensing practices, patient eligibility determination, pain management practices, and standard follow-up care including provision of contraception. Data were collected on paper forms and entered into Epidata. Though the visits targeted all 141 participating PMVs, 21 PMVs were unavailable or unreachable at the time of the last visit to provide survey data. Therefore, 120 PMVs $(n=120)$ who reported dispensing misoprostol were included in the analysis. The visits occurred between 28 June 2016 and 11 December 2018. Online supplemental figure $1 S$ describes the sample of PMVs included in the intervention and the data analysis.

Cross-sectional survey of women obtaining abortion and post-abortion care from PMVs

Durign the period 4-29 June 2018, Ipas conducted a cross-sectional survey of clients who obtained misoprostol at a subsample of PMVs to assess the quality and acceptability of services provided. Drug shops $(n=45)$ were purposely selected based on consistently high records of abortion and post-abortion clients. Women aged 18-49 years who had received services at the selected shops were eligible to participate, and all eligible women purchasing misoprostol during the data collection period were invited to participate $(n=260)$.

A trained female research assistant interviewed clients in an area of the shop with audio and visual privacy. The interviewer obtained written consent before each interview and then collected data using a mobile data collection application on password-protected smart phone, which transferred data to a secure server daily. The study protocol was reviewed and approved by the Nigerian National Health Research Ethics Committee. Results were later shared with the PMVs.

\section{Project definitions}

The initial Ipas training used the 2012 WHOrecommended regimen for misoprostol-alone abortion for pregnancies < 13 weeks' gestation: $800 \mu \mathrm{g}$ misoprostol administered by vaginal or sublingual routes with up to three repeat doses of $800 \mu \mathrm{g}$ administered at intervals of at least 3 hours, but for no longer than 12 hours. ${ }^{21}$ Subsequent training incorporated modifications to the guidelines including information on a shortened dosing interval (3-4hours) and use of buccal administration. PMVs assessed the outcome of the abortion at either a return visit or a telephone consultation and recorded one of three abortion outcomes in the logbook: (1) complete abortion (ie, no additional treatment required), (2) a complication managed by the PMV (eg, excessive bleeding or signs of suspected infection) or (3) a complication referred to a higher-level facility for additional treatment. A positive outcome was a complete abortion without complications.

\section{Analysis}

We conducted a descriptive analysis of the client characteristics and abortion outcomes recorded in PMV logbooks. We also describe PMVs' self-reports of dispensation practices as recorded in the crosssectional survey and stratify the analysis by provider type (ie, nurse/midwife vs $\mathrm{CHO} / \mathrm{CHEW}$ )). We describe clients' sociodemographic characteristics and experience as documented in the cross-sectional client survey and stratified by service requested (ie, abortion or 


\section{Original research}

Table 2 Patent medicine vendors (PMVs)' report of misoprostol dispensation practices for induced abortion by type of PMV provider

\begin{tabular}{|c|c|c|c|c|c|c|c|}
\hline \multirow[b]{2}{*}{ Variable } & \multicolumn{2}{|c|}{ Nurse/midwife $(\mathrm{n}=98)$} & \multicolumn{2}{|c|}{$\mathrm{CHO} / \mathrm{CHEW}(\mathrm{n}=22)$} & \multicolumn{2}{|c|}{ Total $(n=120)$} & \multirow[b]{2}{*}{$P$ value } \\
\hline & $\mathbf{n}$ & $\%$ & $\mathbf{n}$ & $\%$ & $\mathbf{n}$ & $\%$ & \\
\hline Dispense misoprostol without prescription* & 97 & 98.9 & 22 & 100 & 119 & 99.1 & 0.535 \\
\hline \multicolumn{7}{|c|}{ Misoprostol dosage $(\mu \mathrm{g})$ dispensed to help bring on a woman's period if she has missed a periodt } & $<0.001$ \\
\hline$<800$ & 0 & 0 & 1 & 4.5 & 1 & 0.8 & \\
\hline 800 & 1 & 1.0 & 7 & 31.8 & 8 & 6.7 & \\
\hline $1000-1400$ & 5 & 5.1 & 14 & 63.6 & 19 & 15.8 & \\
\hline $1600-2400$ & 92 & 93.9 & 0 & 0 & 92 & 76.7 & \\
\hline Suggested route of misoprostol administration‡ & \multicolumn{2}{|c|}{ Nurse/midwife $(\mathrm{n}=98)$} & \multicolumn{2}{|c|}{$\mathrm{CHO} / \mathrm{CHEW}(\mathrm{n}=22)$} & \multicolumn{2}{|c|}{ Total $(n=120)$} & \\
\hline Vaginal & 78 & 79.6 & 2 & 9.1 & 80 & 66.7 & $<0.001$ \\
\hline Under tongue (sublingual) & 84 & 85.7 & 22 & 100 & 106 & 88.3 & 0.169 \\
\hline In cheek (buccal) & 5 & 5.2 & 19 & 86.4 & 24 & 20.2 & $<0.001$ \\
\hline \multicolumn{8}{|l|}{ Approaches for estimating gestational age of pregnancy $\ddagger$} \\
\hline Last menstrual period & 98 & 100 & 22 & 100 & 120 & 100 & - \\
\hline Bimanual exam & 60 & 61.2 & 0 & 0 & 60 & 50 & $<0.001$ \\
\hline Ultrasound scan & 6 & 6.2 & 2 & 9.1 & 8 & 6.7 & 0.49 \\
\hline Does not estimate & 1 & 1 & 0 & 0 & 1 & 0.8 & 0.815 \\
\hline Provide pain management§ & 94 & 96.9 & 21 & 95.5 & 115 & 96.6 & \\
\hline \multicolumn{8}{|l|}{ Pain management options provided $\neq$} \\
\hline Paracetamol & 8 & 8.2 & 0 & 0 & 8 & 6.7 & 0.035 \\
\hline Diclofenac or Feldene & 80 & 82.5 & 21 & 95.5 & 101 & 84.9 & \\
\hline Buscopan & 0 & 0 & 1 & 4.5 & 1 & 0.8 & \\
\hline Available for follow-up consult & 97 & 99 & 22 & 100 & 119 & 99.2 & 0.634 \\
\hline \multicolumn{8}{|l|}{ When advised to return $\neq$} \\
\hline Pain & 68 & 69.4 & 22 & 100 & 90 & 75 & 0.011 \\
\hline Heavy bleeding & 98 & 100 & 22 & 100 & 120 & 100 & - \\
\hline Fever & 64 & 66 & 22 & 100 & 86 & 72.3 & 0.006 \\
\hline Unusual or bad smelling vaginal discharge & 63 & 64.9 & 22 & 100 & 85 & 71.4 & 0.005 \\
\hline Feeling very sick & 64 & 66 & 22 & 100 & 86 & 72.3 & 0.006 \\
\hline $\begin{array}{l}\text { If no bleeding or cramping during } 2 \text { weeks after } \\
\text { taking the pills }\end{array}$ & 29 & 31.2 & 20 & 90.9 & 49 & 42.6 & $<0.001$ \\
\hline \multicolumn{8}{|c|}{ Services provided for women who report they are still pregnant after taking misoprostolf } \\
\hline Take clinical history & 66 & 67.3 & 20 & 90.9 & 86 & 71.7 & 0.019 \\
\hline Conduct a clinical examination & 58 & 59.2 & 4 & 18.2 & 62 & 51.7 & 0.001 \\
\hline Refer to a facility & 63 & 64.3 & 8 & 36.4 & 71 & 59.2 & 0.004 \\
\hline Reassure woman of outcome(s) & 90 & 92.9 & 12 & 54.5 & 103 & 85.8 & $<0.001$ \\
\hline $\begin{array}{l}\text { Proportion of PMVs who report some clients experience } \\
\text { complications }\end{array}$ & 31 & 31.6 & 1 & 4.5 & 32 & 26.7 & 0.009 \\
\hline Services provided when complications arise & \multicolumn{2}{|c|}{ Nurse/midwife $(\mathrm{n}=31)$} & \multicolumn{2}{|c|}{ CHO/CHEW $(n=1)$} & \multicolumn{2}{|c|}{ Total $(n=32)$} & \\
\hline First aid & 31 & 100 & 0 & 0 & 31 & 96.9 & $<0.001$ \\
\hline Give other/additional medications & 0 & 0 & 1 & 100 & 1 & 3.1 & $<0.001$ \\
\hline Refer to a facility & 31 & 100 & 1 & 100 & 32 & 100 & - \\
\hline
\end{tabular}

*One PMV was missing data on whether misoprostol was provided by prescription.

tRefers to dosage for abortion.

‡Multiple responses possible.

$\S$ Data on pain management were available for a subsample of PMVs $(n=119)$.

CHEW, community health extension worker; CHO, community health officer; PMV, patent medicine vendor. 
Table 3 Women's sociodemographic characteristics and how they learnt of service by type of service received from patent medicine vendors

\begin{tabular}{|c|c|c|c|c|}
\hline & Abortion $(n=193)$ & Post-abortion care $(n=67)$ & Total $(n=260)$ & \\
\hline Characteristic & n (\%) & n (\%) & n (\%) & $P$ value \\
\hline Age (years) & & & & 0.903 \\
\hline $15-19$ & $17(8.8)$ & $7(10.4)$ & $24(9.2)$ & \\
\hline $20-24$ & $33(17.1)$ & $12(17.9)$ & $45(17.3)$ & \\
\hline $25+$ & $143(74.1)$ & $48(71.6)$ & $191(73.5)$ & \\
\hline Relationship status* & & & & 0.826 \\
\hline Married & $132(68.8)$ & $47(70.1)$ & $179(69.1)$ & \\
\hline Living with partner, but not married & $3(1.6)$ & $1(1.5)$ & $4(1.5)$ & \\
\hline Have a steady partner, but not living together & $33(17.2)$ & $13(19.4)$ & $46(17.8)$ & \\
\hline Separated/ivorced & $5(2.6)$ & $0(0)$ & $5(1.9)$ & \\
\hline No steady partner & $19(9.9)$ & $6(9)$ & $25(9.6)$ & \\
\hline Educational attainment & & & & 0.707 \\
\hline No formal/some primary & $15(7.8)$ & $5(7.5)$ & $20(7.7)$ & \\
\hline Completed primary & $11(5.7)$ & $1(1.5)$ & $12(4.6)$ & \\
\hline Some secondary & $22(11.4)$ & $6(9)$ & $28(10.8)$ & \\
\hline Completed secondary & $16(39.4)$ & $30(44.8)$ & $106(40.8)$ & \\
\hline Some tertiary & $31(16.1)$ & $13(19.4)$ & $44(16.9)$ & \\
\hline Completed tertiary & $38(19.7)$ & $12(17.9)$ & $50(19.2)$ & \\
\hline Religious affiliationt & & & & 0.004 \\
\hline Catholic & $30(15.5)$ & $22(32.8)$ & $52(20)$ & \\
\hline Non-Catholic & $89(46.1)$ & $26(38.8)$ & $115(44.2)$ & \\
\hline Islam & $73(37.8)$ & $19(28.4)$ & $92(35.4)$ & \\
\hline None & $1(0.5)$ & $0(0)$ & $1(0.4)$ & \\
\hline \multicolumn{5}{|l|}{ Gestational age (weeks) $†$} \\
\hline$<13$ & $188(97.9)$ & $62(93.9)$ & $250(96.9)$ & 0.108 \\
\hline$\geq 13$ & $4(2.1)$ & $4(6.1)$ & $8(3.1)$ & \\
\hline Heard or received abortion information in past year & $137(71)$ & $38(56.7)$ & $175(67.3)$ & 0.03 \\
\hline \multicolumn{5}{|l|}{ Source of abortion information $\neq$} \\
\hline Friend & $89(65)$ & $21(55.3)$ & $110(62.9)$ & 0.274 \\
\hline Family member & $37(27)$ & $7(18.4)$ & $44(25.1)$ & 0.398 \\
\hline Medical provider & $46(33.6)$ & $17(44.7)$ & $63(36)$ & 0.252 \\
\hline Pharmacist/TBA/CHEW & $4(2.1)$ & $1(1.5)$ & $5(1.9)$ & 0.766 \\
\hline Radio/TV/internet/newspaper & $23(11.9)$ & $13(19.4)$ & $36(13.8)$ & 0.126 \\
\hline Billboards/street theatre/pamphlet & $4(2.1)$ & $1(1.5)$ & $5(1.9)$ & 0.766 \\
\hline Hotline & $0(0)$ & $0(0)$ & $0(0)$ & 0 \\
\hline Peer educators/community leaders/women's group/community-based organisation & $7(3.6)$ & $6(9)$ & $13(5)$ & 0.085 \\
\hline \multicolumn{5}{|l|}{ How learned about abortion services at specific PMV¥ } \\
\hline Friend & $82(42.5)$ & $29(43.8)$ & $111(42.7)$ & 0.91 \\
\hline Family member & $44(22.8)$ & $26(38.8)$ & $70(26.9)$ & 0.01 \\
\hline Medical provider & $45(23.3)$ & $14(20.9)$ & $59(22.7)$ & 0.684 \\
\hline Pharmacist/TBA/CHEW & $2(1)$ & $2(3)$ & $4(1.5)$ & 0.264 \\
\hline Radio/TV/internet/newspaper & $4(2.1)$ & $4(6)$ & $8(3.1)$ & 0.111 \\
\hline Billboards/street theatre/pamphlet & $2(1)$ & $0(0)$ & $2(0.8)$ & 0.403 \\
\hline Hotline & $0(0)$ & $0(0)$ & $0(0)$ & 0 \\
\hline Peer educators/community leaders/women's group/community-based organisation & $2(1)$ & $3(4.5)$ & $5(1.9)$ & 0.07 \\
\hline
\end{tabular}


post-abortion care). All analyses were conducted using SPSS (Version 25.0, 2017; IBM Corp., Armonk, NY, USA).

\section{RESULTS}

The vendors recorded dispensing misoprostol for induced abortion or post-abortion care to a total of 8571 clients. Approximately half the clients $(57.4 \%$ or 4924/8571) were provided with misoprostol for induced abortion.

Table 1 describes the clients requesting misoprostol for abortion and their abortion outcome as recorded in PMV logbooks. Among those with a recorded gestational age $(n=4425)$, most clients $(96 \%)$ reported a gestational age less than 13 weeks. For clients where the misoprostol dose dispensed was recorded $(n=3784)$, $86 \%$ of clients received $800 \mu \mathrm{g}$ or more misoprostol. The PMV also provided pain medication (99.0\%) and reported providing a contraceptive method (92\%). Of clients with an outcome recorded in the logbook $(n=4431)$, most $(86 \%)$ had a complete abortion. A secondary analysis reporting rates of complete abortion by gestational age and misoprostol dose received is reported in online supplemental table $1 S$.

Table 2 provides more detail on the self-reported misoprostol dispensation practices of a subsample of PMVs $(n=120)$ recorded in the cross-sectional survey. When asked the dosage dispensed to a client with a missed period who wanted to bring on her period, most nurses/midwives (94\%) reported providing 800 $\mu \mathrm{g}$ misoprostol three times or more. $\mathrm{CHO} / \mathrm{CHEWs}$ were more likely to report giving a lower dosage (ie, $800 \mu \mathrm{g}$ misoprostol fewer than three times) but most (95\%) still provided $800 \mu \mathrm{g}$ or more. Both nurss/ midwives and $\mathrm{CHO} / \mathrm{CHEW}$ s recommended clients use an optimal route of administration (ie, vaginal, sublingual or buccal misoprostol)

All providers reported that they used a client's menstrual history to estimate gestational age (table 2). Sixty nurses/midwives also reported relying on a bimanual examination for assessing eligibility (61\%) $(\mathrm{p}<0.001)$. Almost all PMVs $(99 \%)$ also indicated they offered clients follow-up consultations. However, advice on when to return differed by provider type: nurses/midwives were less likely than $\mathrm{CHO} / \mathrm{CHEW}$ s to counsel patients to return in the event of pain $(70 \%$ vs $100 \%)$, fever (66\% vs $100 \%)$, unusual or bad smelling vaginal discharge (65\% vs $100 \%)$, feeling sick (66\% vs $100 \%)$ or the absence of bleeding or cramping after taking misoprostol $(31 \%$ vs $91 \%)$ (all $\mathrm{p}<0.05)$. For clients who reported that they were still pregnant after taking misoprostol, nurses/midwives were more likely than $\mathrm{CHO} / \mathrm{CHEW}$ s to report that they would conduct a clinical examination $(59 \%$ vs $18 \%, \mathrm{p}=0.001)$ or refer the client to another health facility (64\% vs $36 \%$, $\mathrm{p}=0.004)$.

Table 3 describes the sociodemographic characteristics of clients $(n=260)$ surveyed at a subsample of PMV sites $(n=37)$ stratified by the type of care requested (ie, induced abortion vs post-abortion care). Women in both groups reported that family $(27 \%)$ or friends $(42 \%)$ informed them about the abortion services at the specific PMV where they sought care.

Table 4 describes women's PMV service experience. Most women (80\%) reported that they were counselled on different treatment options, asked about their questions or concerns (90\%) and given pain medication (94\%). Women seeking both abortion and postabortion care were informed about follow-up care (97\%), when additional care is required (95\%) and the risk of pregnancy post-abortion (97\%). Almost all women reported that they would return to the PMV for future services (99\%) or recommend the PMV to family and friends (100\%).

\section{DISCUSSION}

This intervention provides information on trained Nigerian PMVs' dispensation of misoprostol for abortion and women's experience obtaining this service. Based on logbook data recording misoprostol dispensation to approximately 5000 clients, most women with a recorded outcome (86\%) experienced a complete abortion without requiring either additional care by the PMV or referral to another provider. PMVs self-reported using standard methods for assessing gestational age, providing counselling on optimal routes of misoprostol administration (buccal, sublingual or vaginal), using appropriate drug prescriptions in line with international guidance, and providing some follow-up care and contraceptive services. Both nurses/midwives and $\mathrm{CHOs} / \mathrm{CHEWs}$ provided all these services, although nurses/midwives were more likely to report using a clinical examination to confirm client eligibility or abortion completion or providing the WHO-recommended regimen of up to $2400 \mu \mathrm{g}$ misoprostol. Clients interviewed at a subsample of trained PMVs confirmed that they received comprehensive care, including counselling on drug administration and contraception. Almost all women reported that they would return for the service, if needed, and would recommend it to a friend.

The intervention showed a high level of complete abortion without additional treatment. Assuming conservatively that all cases with missing outcomes $(10 \%)$ required additional care, the rate of complete abortion in this sample, $86 \%$, would still be in the range of effectiveness for misoprostol-alone regimens reported in clinical studies. ${ }^{22} 23$ The rate of complete abortion found in this intervention is similar to rates reported from other studies assessing the effectiveness of self-managed misoprostol-alone abortion. ${ }^{24}$

This article has several methodological limitations. Data reported were collected as part of planned monitoring and evaluation activities and not a prospective study. PMVs were purposively selected, had prior clinical training and were licensed and thus 
Table 4 Women's experience interacting with the patent medicine vendor (PMV) by type of service received from PMV

\begin{tabular}{|c|c|c|c|c|}
\hline & Abortion $(n=193)$ & Post-abortion care $(n=67)$ & Total $(n=260)$ & \\
\hline Experience & n (\%) & n (\%) & n (\%) & $P$ value \\
\hline Counselled on different treatment options & $159(82.4)$ & $48(71.6)$ & $207(79.6)$ & 0.06 \\
\hline Asked about questions or concerns & $182(94.3)$ & $52(77.6)$ & $234(90)$ & $<0.001$ \\
\hline Given sufficient information about care & $191(99)$ & $67(100)$ & $258(99.2)$ & 1 \\
\hline Given pain medication & $181(93.8)$ & $64(95.5)$ & $245(94.2)$ & 0.766 \\
\hline Type of pain medication received & & & & 0.055 \\
\hline Oral NSAID & $144(79.6)$ & $60(93.8)$ & $204(83.3)$ & \\
\hline Oral paracetamol & $8(4.4)$ & $1(1.6)$ & $9(3.7)$ & \\
\hline Intramuscular injection & $18(9.9)$ & $3(4.7)$ & $21(8.6)$ & \\
\hline Other & $11(6.1)$ & $0(0)$ & $11(4.5)$ & \\
\hline Informed about follow-up care & $187(96.9)$ & $67(100)$ & $254(97.7)$ & 0.343 \\
\hline Informed about when additional care required & $179(92.7)$ & $67(100)$ & $246(94.60$ & 0.024 \\
\hline Informed about risk of pregnancy post-abortion & $185(95.5)$ & $66(98.5)$ & $251(96.5)$ & 0.454 \\
\hline Felt services were private & $188(97.4)$ & $67(100)$ & $255(98.1)$ & 0.332 \\
\hline Services well explained & $193(100)$ & $67(100)$ & $260(100)$ & - \\
\hline Allowed to express concerns & $192(95.5)$ & $65(97)$ & $257(98.8)$ & 0.172 \\
\hline PMV was welcoming & $193(100)$ & $67(100)$ & $260(100)$ & - \\
\hline Treated in non-judgmental way & $188(97.4)$ & $67(100)$ & $255(98.1)$ & 0.413 \\
\hline $\begin{array}{l}\text { Mean cost of service (Nigerian Naira) among } \\
\text { clients who paid for service (SD) (range) }\end{array}$ & $2113(1590)(1-15,000)$ & $1348(642)(1450-3000)$ & $1967(1487)(1-15,000)$ & 0.002 \\
\hline No payment & $11(5.7)$ & $24(35.8)$ & $35(13.5)$ & \\
\hline $\begin{array}{l}\text { Perceived affordability of service among clients } \\
\text { who paid for service }\end{array}$ & & & & 0.149 \\
\hline Affordable & 15685.7 & $33(76.7)$ & $189(84)$ & \\
\hline Cost too much & $26(14.3)$ & $10(23.3)$ & $36(16)$ & \\
\hline Reside in same community as PMV shop & $145(75.1)$ & $56(83.6)$ & $201(77.3)$ & 0.155 \\
\hline Counselled on contraception & $186(96.4)$ & $64(95.5)$ & $250(96.2)$ & 0.721 \\
\hline \multicolumn{5}{|l|}{ Methods counselled on* } \\
\hline Condoms & $139(72)$ & $52(77.6)$ & $191(73.5)$ & 0.372 \\
\hline Pills & $152(78.8)$ & $54(80.6)$ & $206(79.2)$ & 0.749 \\
\hline DMPA & $159(82.4)$ & $57(85.1)$ & $216(83.1)$ & 0.613 \\
\hline IUCD & $151(78.2)$ & $55(82.1)$ & $206(79.2)$ & 0.503 \\
\hline Implant & $154(79.8)$ & $51(76.1)$ & $205(78.8)$ & 0.526 \\
\hline Female sterilisation & $35(18.1)$ & $26(38.8)$ & $61(23.5)$ & 0.001 \\
\hline Periodic abstinence/withdrawl & $47(24.4)$ & $28(41.8)$ & $75(28.8)$ & 0.007 \\
\hline Felt coerced to accept a method & $14(13.3)$ & $8(21.1)$ & $22(15.4)$ & 0.258 \\
\hline Received a contraceptive method & $105(54.4)$ & $38(56.7)$ & $143(55.6)$ & 0.743 \\
\hline \multicolumn{5}{|l|}{ Method received } \\
\hline Condoms & $18(17.1)$ & $6(15.8)$ & $24(16.8)$ & \\
\hline Pills & $18(17.1)$ & $11(28.9)$ & $29(20.3)$ & \\
\hline Injection/Depo-Provera & $45(42.9)$ & $11(28.9)$ & $56(39.2)$ & \\
\hline IUCD & $8(7.6)$ & $3(7.9)$ & $11(7.7)$ & \\
\hline Implant & $15(14.3)$ & $7(18.4)$ & $22(15.4)$ & \\
\hline $\begin{array}{l}\text { Learnt about new contraceptive method from } \\
\text { PMV }+\end{array}$ & $107(55.4)$ & $48(71.6)$ & $155(59.6)$ & 0.02 \\
\hline Would return to PMV for future services & $192(99.5)$ & $67(100)$ & $259(99.6)$ & 0.555 \\
\hline
\end{tabular}


Table 4 Continued

\begin{tabular}{|c|c|c|c|c|}
\hline & Abortion $(n=193)$ & Post-abortion care $(n=67)$ & Total $(n=260)$ & \\
\hline Experience & n (\%) & n (\%) & n (\%) & $P$ value \\
\hline Would recommend PMV to family or friends & $193(100)$ & $67(100)$ & $260(100)$ & \\
\hline \multicolumn{5}{|l|}{ Degree of satisfaction } \\
\hline Very satisfied & $166(86)$ & $47(70.1)$ & $213(81.9)$ & 0.005 \\
\hline Mostly satisfied & $25(13)$ & $20(29.9)$ & $45(17.3)$ & \\
\hline Somewhat satisfied & $2(1)$ & $0(0)$ & $2(0.8)$ & \\
\hline Not at all satisfied & $0(0)$ & $0(0)$ & $0(0)$ & \\
\hline
\end{tabular}

${ }^{*}$ Multiple response question.

†A new method refers to any modern contraceptive method previously unknown to the client.

DMPA, depot medroxyprogesterone acetate; IUCD, intrauterine contraceptive device; NSAID, non-steroidal anti-inflammatory drug; PMV, patent medicine vendor.

may not be representative of PMVs without formal medical training. The client logbook did not record the severity or nature of specific complications experienced or how and when the abortion outcome was confirmed and thus may not reflect all the care that the woman received during her treatment. Some women presenting for abortion services may have requested treatment for post-abortion care given stigma around abortion. These patients are not included in the analysis of the abortion logbook data. The PMVs included in the client exit interviews were selected purposively based on the reported number of women receiving services, hence the quality of services reported may not reflect the experiences of women receiving care from PMVs with low clientele numbers. Also validating the results with hospital records or with a subset of women themselves may produce different results. We also acknowledge the risk of sourcing data mainly from the PMVs who are affiliated with the organisation and are part of the intervention. Still, despite these limitations, we believe that these results show that trained PMVs can provide high-quality abortion services.

\section{CONCLUSIONS}

Thousands of women seek abortion care from PMVs, demonstrating that they are an important source of abortion care in Nigeria where abortion is legally restricted. The majority of PMVs in this intervention all had prior professional clinical training, dispensed misoprostol in appropriate dosages, and provided clients with information on drug administration and methods of contraception. Interventions designed to improve PMVs' best practices around the provision of abortion care may help improve the quality of services received by clients. Increasing women's access to accurate information and quality medication for abortion care through PMVs may contribute toward a reduction in Nigeria's mortality and morbidity due to unsafe abortion. Future research and intervention efforts should continue to focus on improving PMVs' training on medication abortion as well as informing women about best practices related to abortion self-care as outlined in the 2019 WHO guideline on self-care and medical management of abortion.

Contributors AJC and KS conceptualised the patent medicine vendor (PMV) evaluation, AC, KS, YAA, ABO and BO drafted the manuscript with input from OO. KS, YAA and $\mathrm{ABO}$ managed the analysis of the PMV logbook and client exit interview (CEI) data with input from all authors into the interpretation of the results. All authors contributed to revising the manuscript and approved the final version.

Funding This project was funded by an anonymous donor.

Disclaimer The funder did not play a role in the study design, collection, analysis, interpretation of the data, the writing of the report or the decision to submit the paper for publication.

\section{Competing interests None declared.}

Patient and public involvement Patients and/or the public were involved in the design, or conduct, or reporting, or dissemination plans of this research. Refer to the Methods section for further details.

\section{Patient consent for publication Not required.}

Ethics approval The National Health Research Ethics Committee in Nigeria approved the protocol for the crosssectional survey of women seeking care from the patent medicine vendors (PMVs). The survey of providers and analysis of case record data from participating PMVs were undertaken as part of routine monitoring and evaluation activities associated with the intervention.

Provenance and peer review Not commissioned; externally peer reviewed.

Data availability statement Data are available upon reasonable request. Deidentified client service, client exit interview and sites survey data that underlie the results reported in this article are available upon reasonable request to the corresponding author (abiolaa@ipas.org) by researchers who provide a methodologically sound proposal following publication.

Open access This is an open access article distributed in accordance with the Creative Commons Attribution Non Commercial (CC BY-NC 4.0) license, which permits others to distribute, remix, adapt, build upon this work noncommercially, and license their derivative works on different terms, provided the original work is properly cited, appropriate credit is given, any changes made indicated, and the use is noncommercial. See: http://creativecommons.org/licenses/by-nc/4. $0 /$.

\section{ORCID iD}

Yinka Abiola Adojutelegan http://orcid.org/0000-0003-47675171 


\section{REFERENCES}

1 World Health Organization (WHO). Medical management of abortion. Geneva, Switzerland: WHO, 2018. https://www. who.int/reproductivehealth/publications/medical-managementabortion/en/

2 Footman K, Scott R, Taleb F, et al. Feasibility of assessing the safety and effectiveness of menstrual regulation medications purchased from pharmacies in Bangladesh: a prospective cohort study. Contraception 2018;97:152-9.

3 Stillman M, Owolabi O, Fatusi AO, et al. Women's selfreported experiences using misoprostol obtained from drug sellers: a prospective cohort study in Lagos state, Nigeria. BMJ Open 2020;10:e034670.

4 Footman K, Keenan K, Reiss K, et al. Medical abortion provision by pharmacies and drug sellers in low- and middleincome countries: a systematic review. Stud Fam Plann 2018;49:57-70.

5 Abortion in Nigeria., 2015Guttmacher Institute. Available: https://www.guttmacher.org/fact-sheet/abortion-nigeria. [Accessed 20 Jun 2020].

6 Bankole A, Adewole IF, Hussain R, et al. The incidence of abortion in Nigeria. Int Perspect Sex Reprod Health 2015;41:170-81.

7 Bell SO, Omoluabi E, OlaOlorun F, et al. Inequities in the incidence and safety of abortion in Nigeria. BMJ Glob Health 2020;5:e001814.

8 World Health Organization (WHO). Trends in maternal mortality: 1990 to 2013. estimates by who, UNICEF, UNFPA, the world bank and the United nations population division. Geneva, Switzerland: WHO, 2014. https://www.who.int/ reproductivehealth/publications/monitoring/maternalmortality-2013/en/

9 Henshaw SK, Adewole I, Singh S, et al. Severity and cost of unsafe abortion complications treated in Nigerian hospitals. Int Fam Plan Perspect 2008;34:040-51.

10 Prada E, Bankole A, Oladapo OT, et al. Maternal near-miss due to unsafe abortion and associated short-term health and socio-economic consequences in Nigeria. Afr J Reprod Health 2015;19:52-62.

11 Beyeler N, Liu J, Sieverding M. A systematic review of the role of proprietary and patent medicine vendors in healthcare provision in Nigeria. PLoS One 2015;10:e0117165.
12 Liu J, Prach LM, Treleaven E, et al. The role of drug vendors in improving basic health-care services in Nigeria. Bull World Health Organ 2016;94:267-75.

13 Schwandt HM, Speizer IS, Corroon M. Contraceptive service provider-imposed restrictions to contraceptive access in urban Nigeria. BMC Health Services Research 2017;17.

14 Okonkwo AD, Okonkwo UP. Community pharmacists and STI management in Abuja Nigeria. Apr Health Sci 2010;10:253-65.

15 Fayemi MM, Oduola OL, Ogbuji QC, et al. The knowledge of emergency contraception and dispensing practices of patent medicine vendors in South West Nigeria. J Public Health Policy 2010;31:281-94.

16 Ujuju C, Adebayo SB, Anyanti J, et al. An assessment of the quality of advice provided by patent medicine vendors to users of oral contraceptive pills in urban Nigeria. J Multidiscip Healthc 2014;7:163-71.

17 Jadesimi A, Okonofua FE. Tackling the unacceptable: Nigeria approves misoprostol for postpartum haemorrhage. J Fam Plann Reprod Health Care 2006;32:213-4.

18 Akiode A, Fetters T, Okoh M. The availability of misoprostol in pharmacies and patent medicine stores in two Nigerian cities. Ebonyi Med J 2010.

19 Bello FA, Fawole B, Oluborode B, et al. Trends in misoprostol use and abortion complications: a cross-sectional study from nine referral hospitals in Nigeria. PLoS One 2018;13:e0209415.

20 Nigerian Federal Ministry of Health. Task-shifting and tasksharing policy for essential health care services in Nigeria, 2014. https://www.health.gov.ng/doc/TSTS.pdf

21 World Health Organization (WHO). Safe abortion: technical and policy guidance for health systems. 2nd EDN. Geneva, Switzerland: WHO, 2012. https://www. who.int/reproductivehealth/publications/unsafe_abortion/ 9789241548434/en/

22 Raymond EG, Harrison MS, Weaver MA. Efficacy of misoprostol alone for first-trimester medical abortion: a systematic review. Obstet Gynecol 2019;133:137-47.

23 Sheldon WR, Durocher J, Dzuba IG, et al. Early abortion with buccal versus sublingual misoprostol alone: a multicenter, randomized trial. Contraception 2019;99:272-7.

24 Moseson H, Herold S, Filippa S, et al. Self-managed abortion: a systematic scoping review. Best Pract Res Clin Obstet Gynaecol 2020;63:87-110. 